\title{
Long-term outcomes of anthroposophic therapy for chronic low back pain: A two-year follow-up analysis
}

This article was published in the following Dove Press journal:

Journal of Pain Research

24 June 2009

Number of times this article has been viewed

\section{Harald J Hamre' \\ Claudia MWitt ${ }^{2}$ \\ Gunver S Kienle' \\ Anja Glockmann' \\ Renatus Ziegler ${ }^{3}$ \\ Stefan N Willich ${ }^{2}$ \\ Helmut Kiene'}

'Institute for Applied Epistemology and Medical Methodology, Freiburg, Germany; ${ }^{2}$ Institute of Social Medicine, Epidemiology, and Health Economics, Charité University Medical Center, Berlin, Germany; ${ }^{3}$ Society for Cancer Research, Arlesheim, Switzerland
Correspondence: Harald J Hamre IFAEMM, Zechenweg 6, D-79|II Freiburg, Germany Tel +497611560307 Fax +497611560306 Email harald.hamre@ifaemm.de
Background: Anthroposophic treatment for chronic low back pain (LBP) includes special artistic and physical therapies and special medications. In a previously published prospective cohort study, anthroposophic treatment for chronic LBP was associated with improvements of pain, back function, and quality of life at 12-month follow-up. These improvements were at least comparable to improvements in a control group receiving conventional care. We conducted a two-year follow-up analysis of the anthroposophic therapy group with a larger sample size.

Methods: Seventy-five consecutive adult outpatients in Germany, starting anthroposophic treatment for discogenic or non-specific LBP of $\geq 6$ weeks' duration participated in a prospective cohort study. Main outcomes were Hanover Functional Ability Questionnaire (HFAQ; 0-100), LBP Rating Scale Pain Score (LBPRS; 0-100), Symptom Score (0-10), and SF-36 after 24 months.

Results: Eighty-five percent of patients were women. Mean age was 49.0 years. From baseline to 24-month follow-up all outcomes improved significantly; average improvements were: HFAQ 11.1 points (95\% confidence interval [CI]: 5.5-16.6; $\mathrm{p}<0.001)$, LBPRS $8.7(95 \%$ CI: 4.4-13.0; $\mathrm{p}<0.001)$, Symptom Score 2.0 (95\% CI: 1.3-2.8; $\mathrm{p}<0.001)$, SF-36 Physical Component Summary 6.0 (95\% CI: 2.9-9.1; p $<0.001)$, and SF-36 Mental Component Summary 4.0 (95\% CI: $1.1-6.8 ; \mathrm{p}=0.007)$.

Conclusion: Patients with chronic LBP receiving anthroposophic treatment had sustained improvements of symptoms, back function, and quality of life, suggesting that larger multicenter rigorous studies may be worthwhile.

Keywords: anthroposophy, drug therapy, eurythmy therapy, low back pain, follow-up studies

\section{Background}

Low back pain (LBP) affects $50 \%-80 \%$ of adults at some point in life $^{1}$ and is a frequent cause of disability, sick-leave, and health service use. ${ }^{2}$ At least $10 \%$ of patients with acute LBP do not improve within four weeks, and $42 \%-75 \%$ are not fully recovered within 12 months. ${ }^{3}$ Standard conventional treatment of chronic LBP is often unsatisfactory. ${ }^{2}$

One complementary therapy used for LBP is anthroposophic medicine (AM). AM acknowledges a spiritual-existential dimension in man, which is assumed to interact with psychological and somatic levels in health and disease. AM therapy for chronic LBP aims to counteract constitutional vulnerability, stimulate salutogenetic self-healing capacities, and strengthen patient autonomy., ${ }^{4,5}$ This is sought to be achieved by counseling, by nonverbal therapies such as AM eurythmy therapy, rhythmical massage therapy, art therapy, and by special AM medications. ${ }^{4}$ 
Eurythmy therapy (Greek: eurythmy, "harmonious rhythm", is an artistic exercise therapy involving cognitive, emotional, and volitional elements. ${ }^{6}$ In eurythmy therapy sessions the patients exercise specific movements with the hands, the feet, or the whole body. Eurythmy movements are related to the sounds of vowels and consonants, to music intervals or to soul gestures, eg, sympathy-antipathy. Between therapy sessions the patients exercise eurythmy movements daily. ${ }^{4}$ Rhythmical massage therapy was developed from Swedish massage; special techniques include lifting movements, rhythmically undulating gliding movements, and complex movement patterns like lemniscates. In AM art therapy the patients engage in painting, drawing, clay modeling, music or speech exercises. AM medications are prepared from plants, minerals, animals, and from chemically defined substances. A key concept of AM medication therapy is typological correspondences between pathophysiological processes in man and formative forces working in minerals, plants, and animals, reflecting a common evolution of man and nature. ${ }^{4,5}$

AM therapy is provided by physicians (counseling, AM medication) and nonmedical therapists (eurythmy, rhythmical massage, art). For patients with chronic LBP the physician will choose among the available AM therapy modalities in order to tailor the treatment to individual needs of the patient.

To date AM therapy for LBP has been evaluated in three observational studies, conducted in specialized settings..$^{7-9}$ We conducted a prospective observational comparative study of outpatients treated by AM physicians or conventional physicians for subacute/chronic LBP. A previously published 12-month analysis comprising $34 \mathrm{AM}$ patients and 28 conventionally treated patients showed improvements of symptoms, back function, and quality of life in both groups. Most improvements (10 of 13 clinical outcomes) were comparable in the two groups, while the AM patients had more outspoken improvements in three quality of life domains. ${ }^{10}$ Study logistics and funding allowed for a prolonged recruitment and follow-up of AM patients but not of the conventionally treated patients. Here we present an analysis of a larger sample of AM patients from this study, followed up for two years.

\section{Methods}

\section{Study design and objective}

This is a follow-up analysis of a prospective observational comparative cohort study of subacute/chronic LBP in a real-world medical setting. ${ }^{10}$ The LBP study ${ }^{10}$ was part of a larger research project on the effectiveness, costs, and safety of AM therapies in outpatients with chronic disease (Anthroposophic Medicine Outcomes Study; AMOS). ${ }^{11}$ The present follow-up analysis of the LBP study concerned the intervention group with patients starting AM therapies for LBP. The primary question was if the improvements in symptoms, back function, and quality of life observed after 12 months in a previous analysis ${ }^{10}$ were confirmed in a larger sample and were maintained at two-year follow-up. Further research questions concerned the use of adjunctive therapies and health services as well as adverse reactions.

\section{Setting, participants, and therapy}

All physicians certified by the Physicians' Association for Anthroposophical Medicine in Germany and working in an office-based practice or worked in outpatient clinics in Germany were invited to participate in the AMOS study. The participating physicians recruited consecutive outpatients starting AM therapy under routine clinical conditions. Patients enrolled from January 1st, 1999 to December 31st, 2005 were included in the present analysis if they fulfilled the eligibility criteria.

Inclusion criteria were

1. Age $17-75$ years

2. LBP of at least six weeks duration

3. Starting AM therapy for LBP: AM-related consultation of at least 30 minutes followed by new prescription of AM medication, or new referral to AM therapy (art, eurythmy, or rhythmical massage).

Exclusion criteria were:

1. Previous back surgery.

2. Any of the following diagnoses: Congenital spinal malformation, spinal infectious or malignant disease, ankylosing spondylitis, Behçet's syndrome, Reiter's syndrome, osteoporosis with vertebral fracture, spinal stenosis, spondylolysis, spondylolisthesis, or fibromyalgia.

3. Previous use of the AM therapy in question (see inclusion criteria No 3) for LBP.

The patients were treated according to the physician's discretion. AM therapy was evaluated as a whole system. ${ }^{12}$

\section{Clinical outcomes}

Primary outcomes were the Hanover Functional Ability Questionnaire (HFAQ) and the Low Back Pain Rating Scale Pain Score (LBPRS) after 24 months.

The HFAQ (German: Funktionsfragebogen Hannover für Rückenschmerzen; FFbH-R) is a self-rating questionnaire of back-specific functional disability. ${ }^{13}$ The HFAQ consists 
of 12 activity-related questions (eg, "Can you bend down to pick up a paper from the floor?") which are answered on three-point Likert scales ("Can do without difficulty"/“Can do, but with some difficulty"/"Either unable to do or only with help"). The HFAQ score ranges from 0 (minimal function) to 100 (optimal function, no limitation); a score of $\leq 70$ points indicates a clinically significant functional limitation. The World Health Organization lists the HFAQ among the three most relevant disease-specific instruments for spinal disorders. ${ }^{14}$

The LBPRS ${ }^{15}$ consists of three back pain and three leg pain items: current pain, worst pain, and average pain during the last seven days, assessed on numerical rating scales from 0 ("no pain") to 10 ("unbearable pain"). The LBPRS ranges from 0 (6× "no pain") to 100 (6× "unbearable pain").

Secondary clinical outcomes were Symptom Score, depressive symptoms, and quality of life. Symptom Score, the severity of one to six most relevant symptoms present at baseline, was assessed by patients on numerical rating scales from 0 ("not present") to 10 ("worst possible"). Depressive symptoms were assessed with the Center for Epidemiological Studies Depression Scale, German version (CES-D; 0-60). ${ }^{16,17}$ Quality of life was assessed with the SF-36 Health Survey (Physical and Mental Component summary measures, eight scales). ${ }^{18}$

All clinical outcomes were documented after $0,3,6,12$, 18 , and 24 months.

\section{Other outcomes}

Use of adjunctive therapies and health services in the pre-study year was documented at study entry, use in the first study year was documented after six and 12 months, and use in the second study year was documented after 18 and 24 months. The following items were documented: back-related physician visits (visits to general practitioners, internists, orthopedic surgeons, neurologists, or psychiatrists), diagnostic imaging (X-rays, computer tomography, magnetic resonance imaging, scintigrams), non-AM medications, physiotherapy, psychotherapy, inpatient hospital and rehabilitation treatment, and sick leave. In addition, back-related surgery was documented during follow-up.

Adverse reactions to medications or therapies were documented by the patients after $6,12,18$ and 24 months and by the physicians after six months. The documentation included cause, intensity (mild/moderate/severe $=$ no/some/ complete impairment of normal daily activities), and therapy withdrawal because of adverse reactions. Serious adverse events (death, life-threatening condition, acute in-patient hospitalization, new disease or accident causing permanent disability, congenital anomaly, new malignancy) were documented by physicians throughout the study.

\section{Data collection}

All data were documented with questionnaires returned in sealed envelopes to the study office. The physicians documented eligibility criteria; the therapists documented AM therapy administration; the physicians as well as patients documented adverse reactions; all other items were documented by the patients, unless otherwise stated. The patient responses were not made available to the physicians. The physicians were compensated 40 Euro (after March 2001: 60 Euro) per included and fully documented patient, while the patients received no compensation.

The data were entered twice by two different persons into Microsoft ${ }^{\circledR}$ Access 97 (Microsoft Corp., Redmond, WA, USA). The two datasets were compared and discrepancies resolved by checking with the original data.

\section{Quality assurance, adherence to regulations}

The study was approved by the Ethics Committee of the Faculty of Medicine Charité, Humboldt University, Berlin, Germany, and was conducted according to the Declaration of Helsinki and largely following the ICH Guideline for Good Clinical Practice E6. Written informed consent was obtained from all patients before enrolment.

\section{Data analysis}

The data analysis was performed on all patients fulfilling the eligibility criteria, using SPSS ${ }^{\circledR}$ 14.0.1 (SPSS Inc., Chicago, IL, USA) and StatXact ${ }^{\circledR}$ 5.0.3 (Cytel Software Corporation, Cambridge, MA, USA). T-test was used for continuous data with normal distribution; Wilcoxon signed-rank test was used for paired continuous data with nonnormal distribution; McNemar test and Fisher's exact test were used for dichotomous data. All tests were two-tailed. Significance criterion was $\mathrm{p}<0.05$. Since this was a descriptive study, no adjustment for multiple comparisons was performed. ${ }^{19}$ Pre-post effect sizes were calculated as standardized response mean (SRM; mean change score divided by the standard deviation of the change score) and classified as minimal $(<0.20)$, small $(0.20-0.49)$, medium (0.50-0.79), and large $(\geq 0.80) .{ }^{20,21}$ Clinical relevance criteria for pre-post changes were $S R M \geq 0.50 .{ }^{22}$ In the main analysis, outcomes were analyzed in patients with evaluable data for each follow-up, without replacement of missing values. 


\section{Results}

\section{Participating physicians and therapists}

The patients were enrolled by 33 physicians with four different qualifications (27 general practitioners, four internists, one psychiatrist, and one anesthesiologist). Comparing these physicians to AM-certified physicians in Germany with the same four qualifications but without study patients $(\mathrm{n}=285)$, no significant differences were found regarding gender ( $57.6 \%$ vs. $59.3 \%$ males), age (mean $46.6 \pm 7.5$ vs. $48.3 \pm 8.1$ years), number of years in practice (18.4 \pm 7.8 vs. $19.5 \pm 9.2$ ), and the proportion of physicians working in primary care $(90.9 \%$ vs. $87.7 \%)$.

The patients were treated by 41 different AM therapists (art, eurythmy, rhythmical massage). Comparing these therapists to certified therapists without study patients ( $\mathrm{n}=1125)$, no significant differences were found regarding gender ( $87.8 \%$ vs. $80.8 \%$ females), age (mean $49.9 \pm 8.2$ vs $50.3 \pm 9.5$ years $)$ or the number of years since therapist qualification ( $10.8 \pm 7.7$ vs. $13.2 \pm 8.7$ years $)$.

\section{Patient recruitment and follow-up}

A total of 103 patients starting AM treatment for LBP were screened for inclusion. Of these patients, 75 fulfilled all eligibility criteria and were included in the analysis. 28 patients were not included; 22 of these were not eligible for the following reasons: LBP of less than six weeks duration $(n=4)$, previous back surgery $(n=4)$, or diagnosis listed in exclusion criteria $(n=14)$. The remaining six patients were potentially eligible for the present analysis but not included in the AMOS study for the following reasons: previous or ongoing use of AM therapy in question $(n=2)$, patients' baseline questionnaire missing $(\mathrm{n}=1)$, patients' and physicians' baseline questionnaire dated $>30$ days apart $(n=2)$, or physician's baseline questionnaire received $>2$ months after enrolment $(\mathrm{n}=1)$. Each physician enrolled 1-2 patients $(n=26$ physicians), $3-5$ patients $(n=4)$, or $6-11$ patients $(n=3)$. A total of $96 \%(n=72 / 75)$ of patients were enrolled by physicians working in primary care.

A total of $88 \%(n=66 / 75)$ of patients returned at least one follow-up questionnaire. The patients were administered a total of 375 questionnaires, out of which 289 (77.1\%) were returned. Follow-up rates were $84 \%(n=63 / 75)$, $83 \%, 80 \%, 72 \%$, and $67 \%$ after $3,6,12,18$, and 24 months, respectively. Respondents $(\mathrm{n}=50)$ and nonrespondents $(n=25)$ of the 24-month follow-up questionnaire did not differ significantly regarding gender, LBP duration, or baseline parameters (HFAQ, LBPRS, Symptom Score). Mean age was $51.1 \pm 11.4$ in respondents and $44.9 \pm 12.2$ in nonrespondents (mean difference 6.2 years, $95 \%$ confidence interval [CI]: $0.5-12.0 ; \mathrm{p}=0.032$ ).

A dropout survey was performed for AMOS patients enrolled for any indication in the last recruitment year (2005) who had not returned the 24-month follow-up questionnaire ( $n=44$ of 119 enrolled patients). Of these 44 patients, two had died for reasons unrelated to therapy and nine had previously refused further study participation. The remaining 33 patients were contacted by telephone: 10 were unreachable, one refused to be interviewed, and 22 patients gave reasons for nonresponding: no time or not interested $(\mathrm{n}=8)$, forgotten $(n=7)$, therapy completed $(n=4)$, disagreement with therapist, therapy discontinued $(\mathrm{n}=1)$, never had therapy $(n=1)$, or deterioration of primary disorder $(n=1)$. The proportion of patients with deterioration, including the two deaths unrelated to therapy, was $6.8 \%(n=3 / 44)$ of dropouts. The corresponding proportion among patients returning the 24-month follow-up questionnaire, assessed by a deterioration of Symptom Score from baseline after 24 months, was 5.4\% $(n=4 / 74)$ of patients $(p=1.000)$.

\section{Baseline characteristics}

The patients were recruited from 11 of 16 German federal states. Age groups were $20-39$ years: $18 \%(n=18 / 75), 40-59$ years: $55 \%(n=41), 60-75$ years: $21 \%(n=16)$ with a mean age of $49.0 \pm 12.0$ years (range $20-74$ years). A total of $85 \%$ $(n=64 / 75)$ of the patients were women.

Compared with the German population, patients had higher educational and occupational levels and were less frequently regular smokers, daily alcohol consumers, and overweight; patients were more often living alone, whereas more patients engaged in sports than in the population. Sociodemographic status was similar to the population regarding unemployment, income, and severe disability status and less favorable for work disability pension and sick leave (Table 1).

Median LBP duration was 7.0 years (Interquartile range [IQR]: $2.5-18.0$, mean $10.7 \pm 10.6$ years). The main diagnosis, classified by International Classification of Diseases, Tenth Edition (ICD-10), was M54 Dorsalgia ( $55 \%$ of patients, $n=41 / 75$ ), M51 Other intervertebral disc disorders (19\%), M42 Spinal osteochondrosis (11\%), M41 Scoliosis (9\%), M47 Spondylosis (4\%), and other (3\%). One-fourth of patients had lumbar disc disease with nerve root compression; half of patients had a clinically relevant limitation in back function (Table 1).

A current comorbid disease was present in 79\% (67/75) of patients, with a median of 2.0 (IQR: 1.0-3.0) comorbid diseases per patient. Most common comorbid diseases, 
Table I Baseline data of study population

\begin{tabular}{|c|c|c|c|c|c|}
\hline \multirow[t]{2}{*}{ Items } & \multirow[t]{2}{*}{ Subgroup } & \multicolumn{2}{|c|}{ Study patients } & \multirow{2}{*}{$\frac{\text { German population }}{\%}$} & \multirow[t]{2}{*}{ Source } \\
\hline & & $\mathbf{N}$ & $\%$ & & \\
\hline \multirow[t]{3}{*}{ Education $^{29}$} & Low (level I ) & $11 / 75$ & $15 \%$ & $43 \%$ & \multirow[t]{3}{*}{30} \\
\hline & Intermediate (level 2) & $38 / 75$ & $51 \%$ & $43 \%$ & \\
\hline & High (level 3) & $26 / 75$ & $35 \%$ & $14 \%$ & \\
\hline Wage earners & Economically active patients & $4 / 38$ & $11 \%$ & $18 \%$ & 31 \\
\hline Unemployed during last 12 months & Economically active patients & $4 / 38$ & $11 \%$ & $10 \%$ & 31 \\
\hline Living alone & & $22 / 74$ & $30 \%$ & $21 \%$ & 31 \\
\hline Net family income $<900 €$ per month & & $11 / 57$ & $19 \%$ & $16 \%$ & 31 \\
\hline \multirow[t]{2}{*}{ Alcohol use daily (patients) vs almost daily (Germany) } & Male & $0 / 11$ & $0 \%$ & $28 \%$ & \multirow[t]{2}{*}{32} \\
\hline & Female & $2 / 64$ & $3 \%$ & $11 \%$ & \\
\hline \multirow[t]{2}{*}{ Regular smoking } & Male & $2 / 11$ & $18 \%$ & $37 \%$ & \multirow[t]{2}{*}{33} \\
\hline & Female & $4 / 64$ & $6 \%$ & $28 \%$ & \\
\hline Sports activity $\geq$ I hour weekly & Age $25-69$ & $34 / 7 \mid$ & $48 \%$ & $39 \%$ & 34 \\
\hline \multirow[t]{2}{*}{ Body mass index $\geq 25$ (overweight) } & Male & $4 / 11$ & $36 \%$ & $56 \%$ & \multirow[t]{2}{*}{31} \\
\hline & Female & $29 / 62$ & $45 \%$ & $39 \%$ & \\
\hline Permanent work disability pension & & $7 / 74$ & $9 \%$ & $3 \%$ & 35 \\
\hline Severe disability status & & $10 / 74$ & $14 \%$ & $12 \%$ & 36 \\
\hline Sick leave days in the last 12 months (mean \pm SD) & Economically active patients & \multicolumn{2}{|c|}{$38.3 \pm 58.0$} & 17.0 & \multirow[t]{5}{*}{37} \\
\hline \multirow[t]{4}{*}{ Low back pain duration } & 6 weeks -2 months & 4 & $5 \%$ & & \\
\hline & $3-5$ months & 1 & $1 \%$ & & \\
\hline & 6-11 months & 3 & $4 \%$ & & \\
\hline & $\geq 12$ months & 67 & $89 \%$ & & \\
\hline $\begin{array}{l}\text { Lumbar disc herniation or protrusion with nerve root } \\
\text { compression }\end{array}$ & & $17 / 75$ & $23 \%$ & & \\
\hline $\begin{array}{l}\text { HFAQ } \leq 70 \text { points = clinically relevant limitation in } \\
\text { back function }\end{array}$ & & $34 / 73$ & $47 \%$ & $<22 \%$ & 38 \\
\hline CES-D $\geq 24$ points $=$ depressive range & & $25 / 67$ & $37 \%$ & $17 \%$ & 17 \\
\hline
\end{tabular}

Abbreviations: CES-D, Center for Epidemiological Studies Depression Scale, German version; HFAQ, Hanover Functional Ability Questionnaire.

classified by ICD-10, were F00-F99 Mental disorders (15.6\%, 26 of 167 diagnoses), M00-M99 Musculoskeletal diseases (15.6\%), I00-I99 Cardiovascular disorders (15.0\%), E00-E90 Endocrine, nutritional and metabolic diseases (10.2\%), and K00-K93 Digestive system diseases (9.6\%). One-third of patients had clinically relevant depressive symptoms (Table 1).

\section{Therapy}

At study enrolment, the duration of the consultation with the AM physician was $<30 \mathrm{~min}$ in $67 \%(\mathrm{n}=50 / 75)$ of patients, $30-44 \mathrm{~min}$ in $25 \%, 45-59 \mathrm{~min}$ in $5 \%$, and $\geq 60 \mathrm{~min}$ in $3 \%$ of patients. At enrolment one patient started AM medical treatment provided by the physician, while the remaining 74 patients were referred to AM eurythmy/art/massage therapy. Of these 74 patients, $82 \%$ $(\mathrm{n}=61)$ had the planned AM therapy, 1\% $(\mathrm{n}=1)$ did not have AM therapy, and for $16 \%(\mathrm{n}=12)$ the AM therapy documentation was incomplete. AM therapies used were eurythmy therapy ( $\mathrm{n}=45$ patients), rhythmical massage therapy ( $n=13)$, and art therapy ( $n=3$, with the therapy modality painting/drawing/clay in all three cases). The AM eurythmy/art/massage therapy started median 12 days (IQR: 3-38) days after enrolment. Median therapy duration was 98 days (IQR: 70-146 days), median number of therapy sessions was 12 (IQR: 10-12). AM medications were used by $69 \%(52 / 75)$ of patients.

The use of adjunctive therapies, health services, and sick leave was compared between the pre-study year and the first and second years, respectively (see Methods for details). No items changed significantly in any period. Back-related surgery occurred in one patient, who had surgery for a coccygeal fistula in the second study year. 


\section{Clinical outcomes}

HFAQ, LBPRS, Symptom Score, CES-D, and the ten SF-36 scores improved significantly between baseline and nearly all subsequent follow-ups (66 significant and four nonsignificant improvements in 70 pre-post comparisons). For nearly all outcomes, the most pronounced improvement occurred during the first six months (Figures 1-5). Effect sizes for the 0-24-month comparisons were large for two outcomes (SF-36 Bodily Pain), medium for seven outcomes, and small for six outcomes (Table 2).

Comparing the improvements from baseline to last follow-up of the present sample $(n=49$ evaluable patients after 24 months) to the corresponding improvements of the previously published analysis of a smaller sample from the same project $\left(\mathrm{n}=34\right.$ patients after 12 months, $\left.{ }^{10}\right)$ differences between the two analyses were minimal (less than 0.2 standard deviations [SD]) for 11 outcomes and small (0.20-0.22 SD) for two outcomes (SF-36 Role Emotional and SF-36 Bodily Pain), both of which showed more outspoken improvement in the present analysis.

Whereas the main analysis comprised patients with evaluable data for each follow-up, we performed sensitivity analyses of the 0-24-month improvements of HFAQ and LBPRS, replacing missing values with the last observation carried forward (Table 2). Compared to the main analysis, the average improvement of HFAQ was increased by $6 \%$

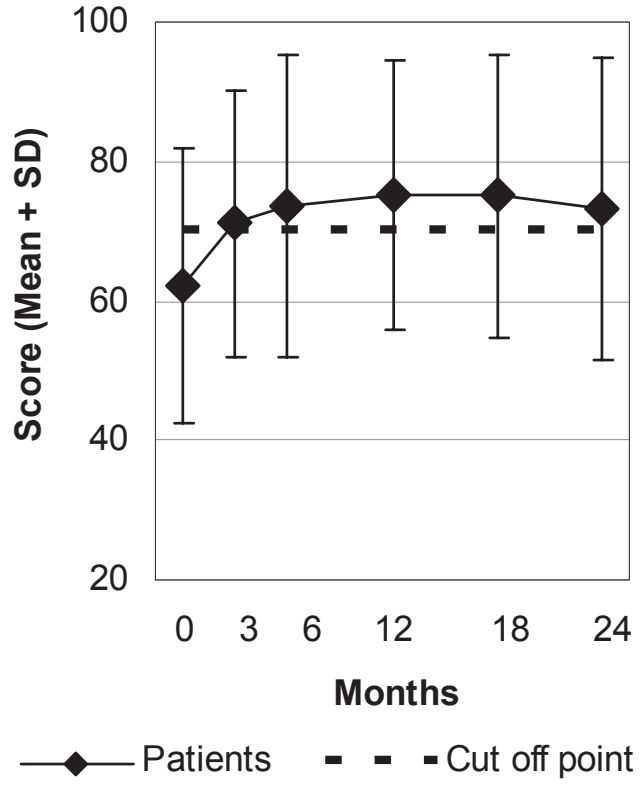

Figure I Hanover Functional Ability Questionnaire (HFAQ).

Notes: Range: 0 , “minimal function"; 100, “optimal function". ${ }^{3}$ Cut off point: A score of $\leq 70$ points indicates a clinically significant functional limitation.
$(11.04 \rightarrow 11.71$ points) while the improvement of LBPRS was decreased by $9 \%(8.71 \rightarrow 7.92$ points $)$.

\section{Other outcomes}

One adverse reaction to AM treatment was documented (mild headache from eurythmy therapy, which was not stopped due to this reaction). Other reported adverse reactions referred to acupuncture ( $\mathrm{n}=1$ patient), psychotherapy $(\mathrm{n}=1)$, and non-AM medications $(\mathrm{n}=12)$.

Two serious adverse events occurred: A 61-year-old woman hospitalized for severe depression died from an accident, possibly suicide. A 42-year-old woman was acutely hospitalized due to an exacerbation of a coexisting Löfgren syndrome, from which she recovered completely. These events occurred 23 months and six months after study enrolment, respectively, and were not related to any therapy or medication.

\section{Discussion}

\section{Main findings}

This is a two-year follow-up analysis of the first study of comprehensive AM treatment for LBP in primary care. We studied 75 outpatients starting AM treatment (mainly eurythmy therapy, rhythmical massage therapy, and medications) for chronic LBP. A previous 12-month analysis had shown improvements in pain, back function, and quality of life under AM treatment, comparable to or more extensive

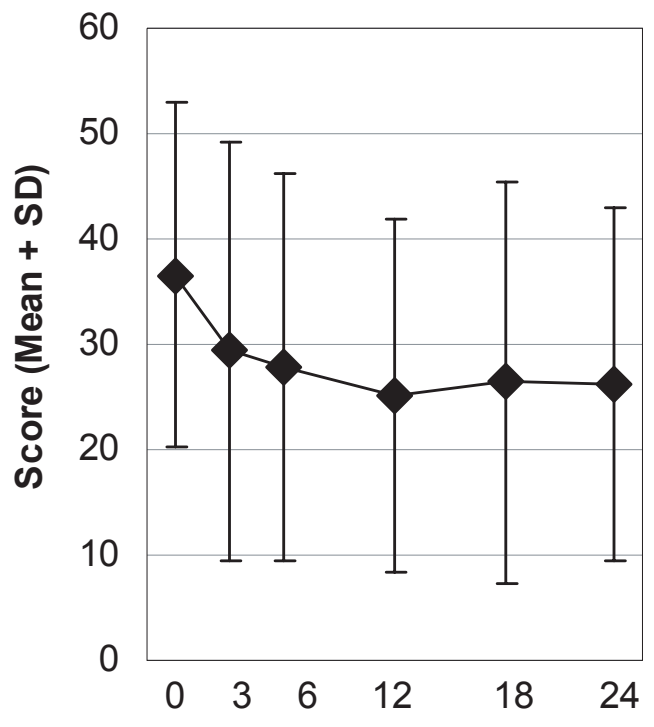

Months

Figure 2 Low Back Pain Rating Scale (LBPRS) Pain Score. Notes: Range: 0, “no pain"; 100, “unbearable pain”. ${ }^{5}$ 


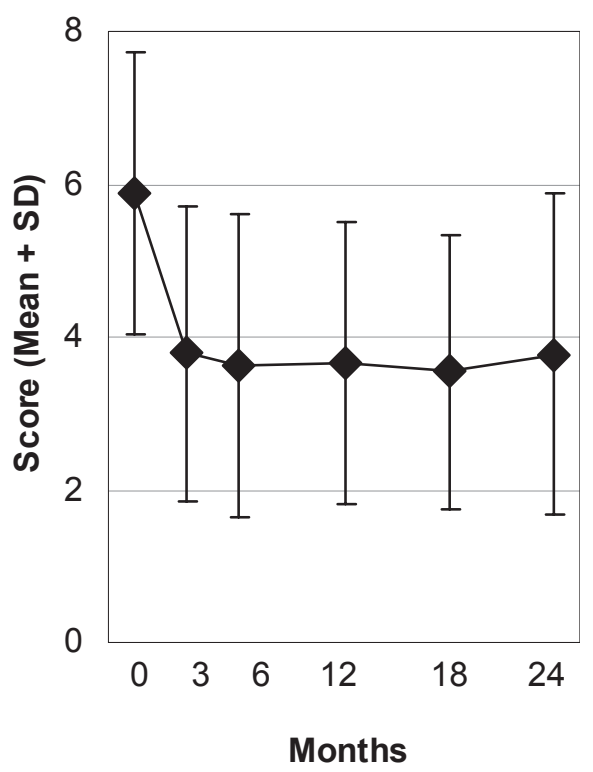

Figure 3 Symptom Score.

Notes: Range: 0 "not present"; 10 "worst possible".

than improvements in patients receiving conventional care. ${ }^{10}$ The present follow-up analysis of AM patients confirmed these improvements in a larger sample and showed that the improvements were maintained at two-year follow-up. Most improvements were clinically relevant (large 0-24-month effect size for SF-36 Bodily Pain, medium effect sizes for seven out of 13 remaining clinical outcomes). Comparing the pre-study year to the first and the second year after study enrolment, the use of non-AM adjunctive therapies and of health services did not increase. Adverse reactions to AM treatment occurred in only one patient.

\section{Strengths and limitations}

Strengths of this study include a detailed assessment of the therapy setting and therapy-related factors, a standardized assessment of back pain and function as well as quality of life, a long follow-up period, and a high representativeness: $10 \%$ of all AM-certified physicians in Germany participated, the participating AM physicians and therapists resembled all eligible physicians and therapists with respect to sociodemographic characteristics, and $93 \%$ of screened and eligible patients were enrolled. These features suggest that the study to a high degree mirrors contemporary AM practice.

The main research question of the present analysis concerned the magnitude of long-term improvements. A limitation in this respect is the increasing long-term dropout rate $(20 \%, 28 \%$, and $33 \%$ after 12,18 , and 24 months, respectively). Dropouts did not differ from evaluable patients regarding baseline characteristics (except dropouts were younger, which would not be associated with a worse outcome ${ }^{23}$ ), and in a telephone survey of a different subset of patients from the AMOS project, the proportion of patients with clinical deterioration at 24-month follow-up was comparable in dropouts and respondents. In a sensitivity analysis of the primary outcomes, replacing missing values in dropouts with their last observation carried forward, improvements were reduced by maximum $9 \%$. A general
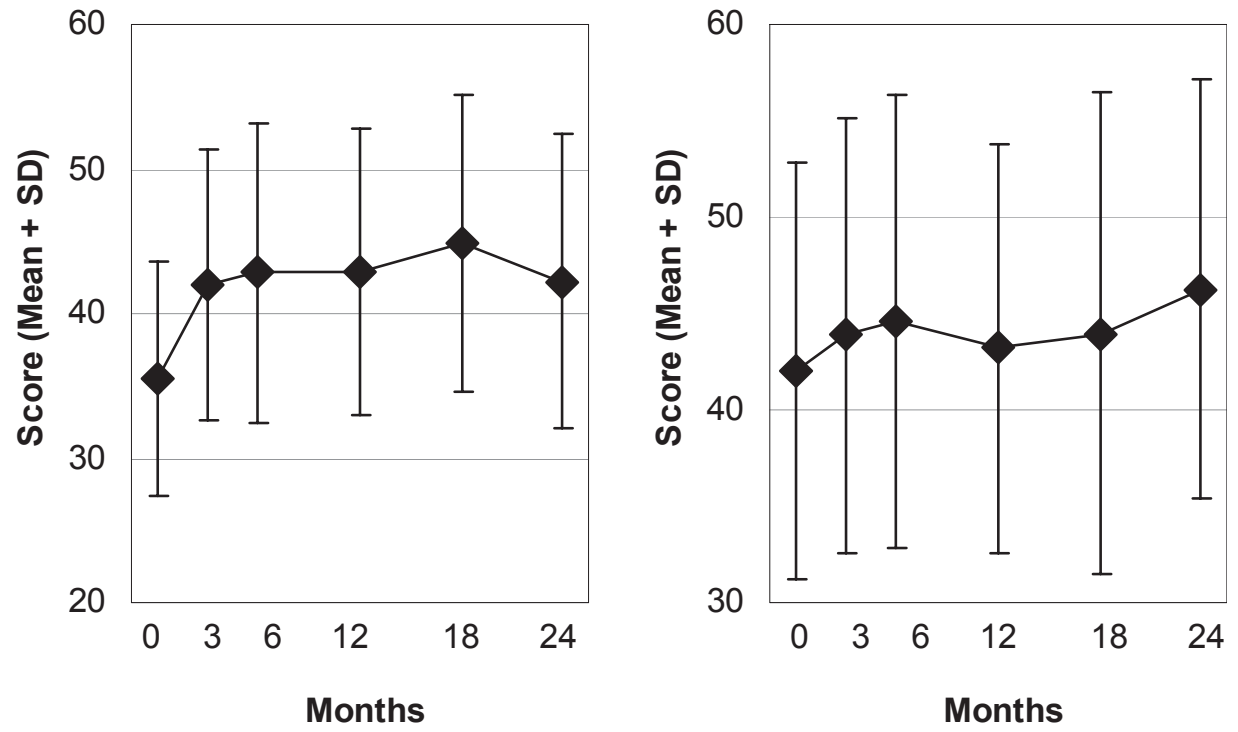

Figure 4 SF-36 Physical Component (left) and Mental Component (right) summary measures. Note: Higher scores indicate better health. 


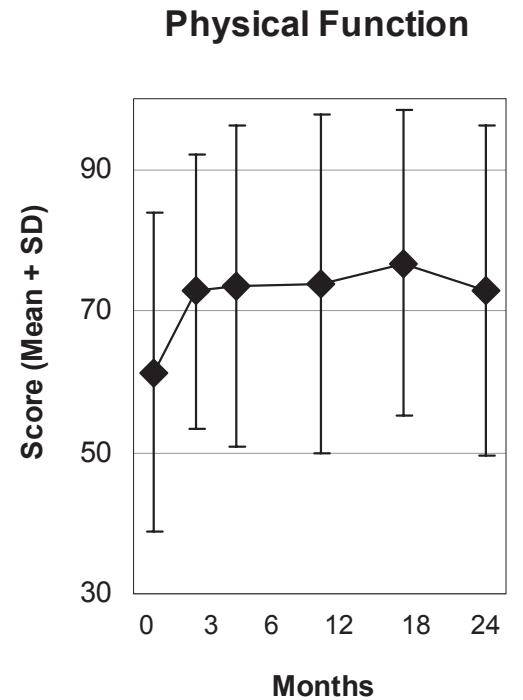

Social Function

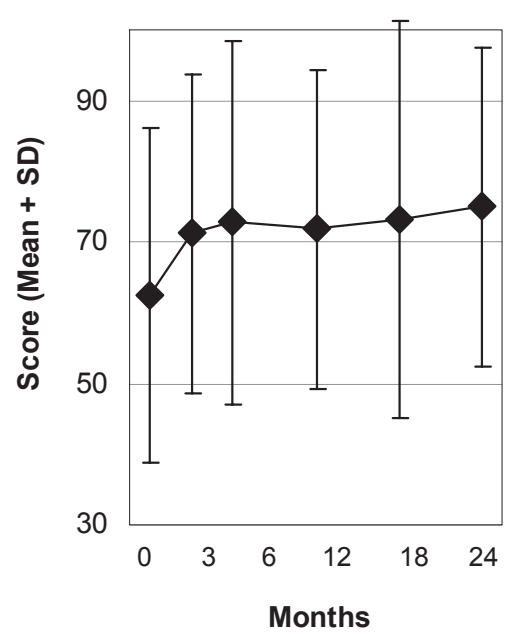

Role Physical

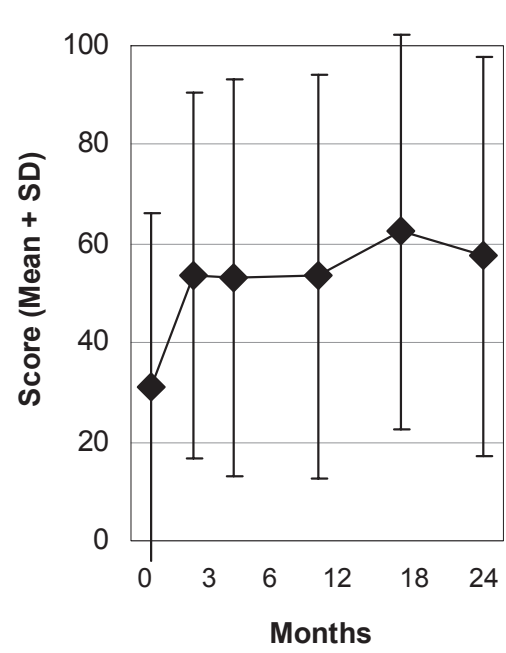

Mental Health

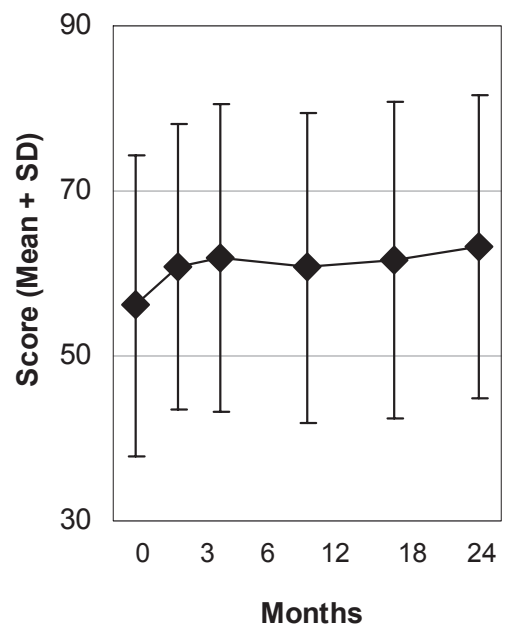

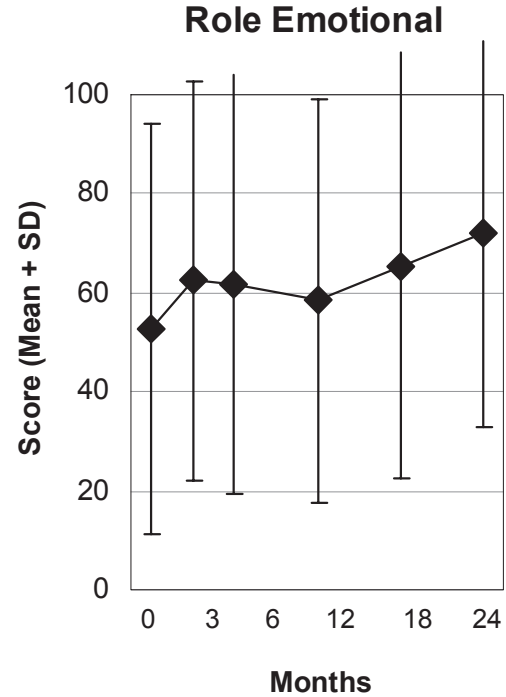

Bodily Pain

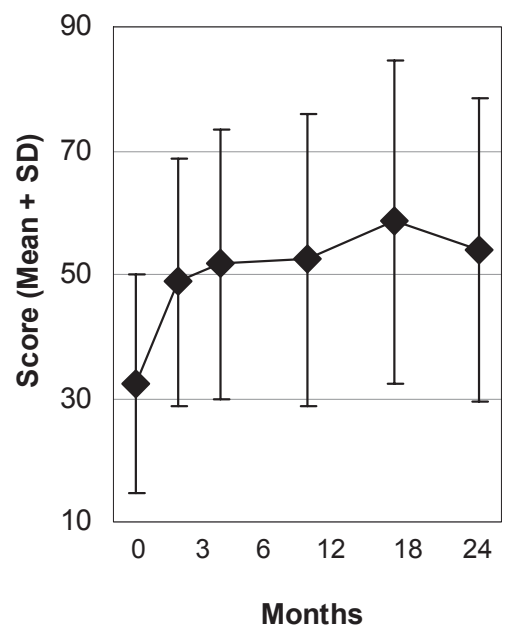

Vitality
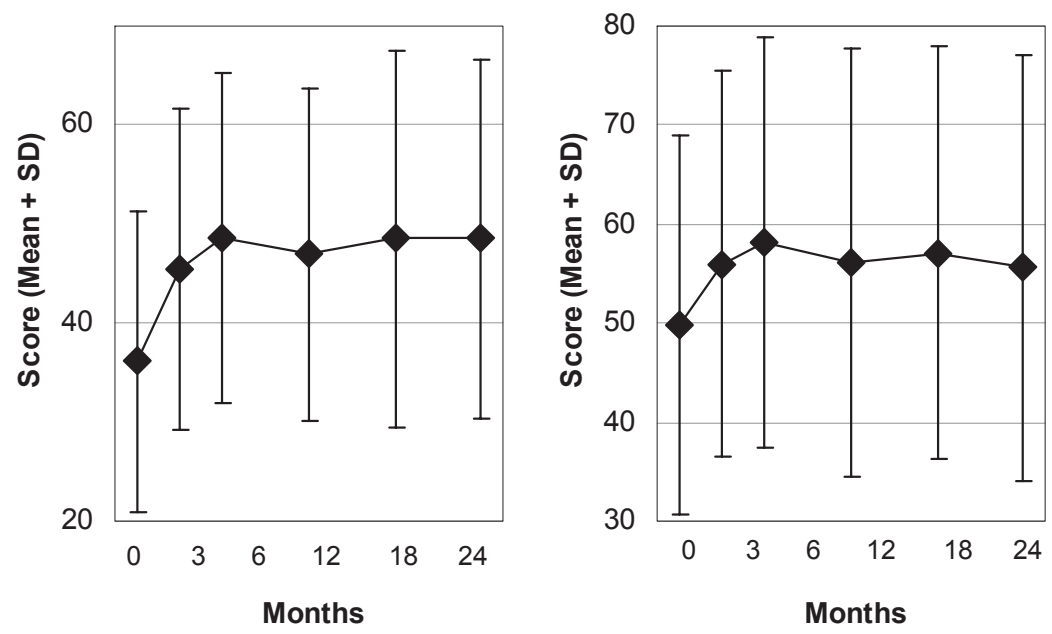

Figure 5 SF-36 Scales.

Notes: Range: 0-100. Higher scores indicate better health. 
explanation for late dropout is the tendency of study subjects to fail to respond to repeated questionnaires. Nevertheless, since LBP is a recurring disorder, we cannot exclude that some late dropouts might have relapsed. A general limitation of the analysis is the modest sample size.

This analysis assessed AM as a whole system. ${ }^{12}$ Supplementary subgroup analysis was possible for patients referred to eurythmy therapy and showed similar improvements in this group, while the sample size of the other therapy modality subgroups (medical, art, rhythmical massage) did not allow for subgroup analysis.

Since the study had a long recruitment period, the study physicians were not able to participate throughout the period and to screen and enroll all eligible patients (criteria: see Methods section). For a different subset of patients from the AMOS project (patients referred to AM therapies and enrolled before April 1st, 2001), it was estimated that physicians enrolled every fourth eligible patient. ${ }^{24}$ This selection could bias results if physicians were able to predict therapy response and if they preferentially screened and enrolled such patients for whom they expected a particularly favorable outcome. In this case one would expect the degree of selection (the proportion of eligible vs. enrolled patients) to correlate positively with clinical outcomes. That was not the case, the correlation was almost zero $(-0.04)$. This analysis $^{24}$ does not suggest that physicians' screening of eligible patients was affected by selection bias.

Because 13 clinical outcomes were analyzed with a total of 17 comparisons at 24-month follow-up (Table 2), the issue of multiple hypothesis-testing arises. ${ }^{19}$ However, all 17 comparisons showed significant improvements and 11 comparisons had p-values $\leq 0.001$.

Table 2 Clinical outcomes 0-24 months

\begin{tabular}{|c|c|c|c|c|c|c|}
\hline \multirow[t]{2}{*}{ Analysis/Outcome (range) } & \multirow[t]{2}{*}{$\mathbf{N}$} & \multirow{2}{*}{$\frac{0 \text { months }}{\text { Mean (SD) }}$} & \multirow{2}{*}{$\begin{array}{l}24 \text { months } \\
\text { Mean (SD) }\end{array}$} & \multicolumn{2}{|c|}{ 0-6 month difference } & \multirow[t]{2}{*}{ SRM } \\
\hline & & & & Mean $(95 \% \mathrm{Cl})^{\mathrm{a}}$ & P-value & \\
\hline \multicolumn{7}{|c|}{$\begin{array}{l}\text { Main analysis: patients with evaluable } \\
\text { data at } 0 \text { and } 24 \text { months }\end{array}$} \\
\hline \multicolumn{7}{|l|}{ HFAQ $(0-100)$} \\
\hline - All therapies & 46 & $61.63(19.77)$ & $72.68(21.45)$ & II.04 (5.52-16.57) & $<0.001$ & 0.59 \\
\hline - Eurythmy therapy & 31 & $61.62(19.62)$ & $71.24(21.04)$ & $9.61(3.25-15.98)$ & 0.004 & 0.55 \\
\hline \multicolumn{7}{|l|}{ LBPRS $(0-100)$} \\
\hline - All therapies & 47 & $34.99(15.10)$ & $26.28(16.91)$ & $8.7 I(4.4 I-13.0 I)$ & $<0.001$ & 0.59 \\
\hline - Eurythmy therapy & 32 & $33.93(14.60)$ & $25.52(16.93)$ & $8.4 \mid(3.57-13.24)$ & 0.001 & 0.66 \\
\hline Symptom Score (0-10) & 49 & $5.79(2.05)$ & $3.76(2.12)$ & $2.04(1.30-2.77)$ & $<0.001$ & 0.79 \\
\hline CES-D (0-60) & 41 & $20.14(9.93)$ & I 5.54 (II.09) & $4.60(1.37-7.84)$ & 0.006 & 0.45 \\
\hline SF-36 Physical Component & 46 & $35.73(7.57)$ & $4 I .72(|0.3|)$ & $5.99(2.88-9.11)$ & $<0.001$ & 0.57 \\
\hline SF-36 Mental Component & 46 & $42.27(10.03)$ & $46.22(10.89)$ & $3.95(1.13-6.78)$ & 0.007 & 0.42 \\
\hline \multicolumn{7}{|l|}{ SF-36 scales $(0-100)$} \\
\hline - Physical Function & 48 & $63.65(20.10)$ & $72.06(23.47)$ & $8.41(1.68-15.15)$ & 0.015 & 0.36 \\
\hline - Role Physical & 49 & $30.6 I(34.7 I)$ & $56.63(40.11)$ & $26.02(14.12-37.93)$ & $<0.001$ & 0.63 \\
\hline - Role Emotional & 47 & $53.90(42.02)$ & $72.34(38.27)$ & I8.44 (6.57-30.3I) & 0.003 & 0.46 \\
\hline - Social Functioning & 49 & $64.29(23.52)$ & $74.74(22.75)$ & $10.46(4.49-16.43)$ & 0.001 & 0.50 \\
\hline - Mental Health & 49 & $56.16(16.75)$ & $63.33(18.59)$ & $7.16(2.19-12.13)$ & 0.006 & 0.41 \\
\hline - Bodily Pain & 49 & $32.78(17.45)$ & $53.94(24.74)$ & 21.16 (I3.83-28.49) & $<0.001$ & 0.83 \\
\hline - Vitality & 49 & $36.26(14.11)$ & $48.16(18.13)$ & II.9| (7.59-16.22) & $<0.001$ & 0.79 \\
\hline - General Health & 49 & $49.38(19.20)$ & $55.34(21.77)$ & $5.96(1.4 I-10.50)$ & 0.011 & 0.38 \\
\hline \multicolumn{7}{|l|}{$\begin{array}{l}\text { Sensitivity analysis: Last value } \\
\text { carried forward }\end{array}$} \\
\hline HFAQ & 73 & $62.13(19.64)$ & 73.83 (19.95) & II.7I (7.6I-I5.80) & $<0.001$ & 0.67 \\
\hline LBPRS & 72 & $36.61(16.40)$ & 28.69 (I8.52) & $7.92(4.7|-| 1.13)$ & $<0.001$ & 0.63 \\
\hline
\end{tabular}

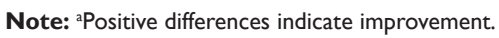

Abbreviations: CES-D, Center for Epidemiological Studies Depression Scale, German version; Cl, confidence interval; HFAQ, Hanover Functional Ability Questionnaire; LBPRS, Low Back Pain Rating Scale Pain Score; SD, standard deviation; SRM, standardized response mean effect size (minimal: $<0.20$, small: 0.20-0.49, medium: 0.50-0.79, large: $\geq 0.80$ ). 


\section{Agreement with existing literature}

Previous studies have found beneficial effects of AM therapies for nonspecific LBP (AM rhythmic embrocation therapy $^{8}$ ) as well as discogenic LBP (subcutaneous injections of $\mathrm{AM}$ medications ${ }^{7}$ comprehensive inpatient AM therapy. ${ }^{9}$ ) The last study also found reduced use of nonsteroid anti-inflammatory drugs and muscle relaxants and earlier return to work after AM therapy, compared to conventional inpatient treatment. ${ }^{9}$ In accordance with these studies, conducted in specialized settings, we have observed clinically relevant improvement in symptoms, back function, and quality of life following AM therapies in a primary care setting. ${ }^{10}$ The present analysis confirms these findings in a larger sample and shows that improvements can be maintained for up to two years.

\section{Study implications}

In this study, AM therapies for chronic LBP were associated with substantial long-term improvement of symptoms, back function, and of quality of life without increase in the use of adjunctive therapies or health services. The improvement in back function, assessed by HFAQ, was at least of the same order of magnitude as corresponding improvements in other German LBP cohorts receiving other treatments and followed up for 12-24 months. ${ }^{25-28}$

Some patients will not profit from standard therapies for LBP. Other patients discontinue standard therapies due to adverse reactions or reject them because therapies are passive (eg, drugs) or too mechanical-repetitive (exercise physiotherapy). In this context, AM seems a promising treatment option for chronic LBP. It should be noted, however, that eurythmy therapy, which was used by most patients in this study, entails daily exercises of artistic movements over a period of several months, which requires sustained motivation.

\section{Conclusions}

In this follow-up analysis of patients receiving AM therapies for chronic LBP, improvements of symptoms, back function, and quality of life were found in a larger sample size and were maintained at two-year follow up, suggesting that larger multicenter rigorous studies may be worthwhile.

\section{Disclosure}

Within the last five years HJH and GSK have received restricted research grants from the pharmaceutical companies Weleda and Wala, who produce AM medications. Otherwise all authors declare that they have no competing interests.
This study was funded by the Software-AG Stiftung and the Innungskrankenkasse Hamburg, with supplementary grants from the Helixor Stiftung, the Mahle Stiftung, and the Zukunftsstiftung Gesundheit. The sponsors had no influence on design and conduct of the study; collection, management, analysis or interpretation of the data; or preparation, review or approval of the manuscript. We thank Wilfried Tröger for helpful discussions. Our special thanks go to the study physicians, therapists, and patients for participating. HJH, CMW, GSK, SNW, and HK contributed to study design. $\mathrm{HJH}, \mathrm{AG}$, and $\mathrm{HK}$ contributed to data collection. HJH, RZ, and HK wrote the analysis plan, $\mathrm{HJH}$ and AG analyzed data. $\mathrm{HJH}$ was principal author of the paper, had full access to all data, and is guarantor. All authors contributed to manuscript drafting and revision and approved the final manuscript.

\section{References}

1. Rubin DI. Epidemiology and risk factors for spine pain. Neurol Clin. 2007;25(2):353-371.

2. Mounce K. Back pain. Rheumatology (Oxford). 2002;41(1):1-5.

3. Hestbaek L, Leboeuf-Y de C, Manniche C. Low back pain: what is the long-term course? A review of studies of general patient populations. Eur Spine J. 2003;12(2):149-165.

4. Ritchie J, Wilkinson J, Gantley M, Feder G, Carter Y, Formby J. A model of integrated primary care: anthroposophic medicine. London: Department of General Practice and Primary Care, St Bartholomew's and the Royal London School of Medicine, Queen Mary, University of London; 2001.

5. Kienle GS, Kiene H, Albonico HU. Anthroposophic medicine: effectiveness, utility, costs, safety. Stuttgart, New York: Schattauer Verlag; 2006.

6. Majorek M, Tüchelmann T, Heusser P. Therapeutic Eurythmy-movement therapy for children with attention deficit hyperactivity disorder (ADHD): a pilot study. Complement Ther Nurs Midwifery. 2004;10(1):46-53.

7. Kienle GS, Kiene H, Albonico HU. [Comparison of acupuncture and paravertebral injections in the treatment of lumbosciatic pain. A retrospective study of 253 patients in a pain clinic]. In: Anthroposophic medicine: effectiveness, utility, costs, safety. Stuttgart, New York: Schattauer Verlag; 2006. p. 141-142.

8. Ostermann T, Blaser G, Bertram M, Michalsen A, Matthiessen PF, Kraft K. Effects of rhythmic embrocation therapy with solum oil in chronic pain patients: a prospective observational study. Clin J Pain. 2008;24(3):237-243.

9. Kienle GS, Kiene H, Albonico HU. [Retrospective comparison of anthroposophic versus conventional treatment of intervertebral disc disease]. In: Anthroposophic medicine: effectiveness, utility, costs, safety. Stuttgart, New York: Schattauer Verlag; 2006. p. 140-141.

10. Hamre HJ, Witt CM, Glockmann A, et al. Anthroposophic vs. conventional therapy for chronic low back pain: a prospective comparative study. Eur J Med Res. 2007;12(7):302-310.

11. Hamre HJ, Becker-Witt C, Glockmann A, Ziegler R, Willich SN, Kiene H. Anthroposophic therapies in chronic disease: The Anthroposophic Medicine Outcomes Study (AMOS). Eur J Med Res. 2004;9(7): 351-360.

12. Boon H, MacPherson H, Fleishman S, et al. Evaluating complex healthcare systems: a critique of four approaches. Evid Based Complement Alternat Med. 2007;4(3):279-285. 
13. Kohlmann T, Raspe H. Der Funktionsfragebogen Hannover zur alltagshaften Diagnostik der Funktionsbeeinträchtigung durch Rückenschmerzen (FFbH-R). [Hannover Functional Questionnaire in ambulatory diagnosis of functional disability caused by backache]. Rehabilitation (Stuttg). 1996;35(1):I-VIII.

14. World Health Organization. The burden of musculoskeletal conditions at the start of the new millennium. WHO Technical Report Series 919. Geneva: World Health Organization; 2003.

15. Manniche C, Asmussen K, Lauritsen B, Vinterberg H, Kreiner S, Jordan A. Low Back Pain Rating scale: validation of a tool for assessment of low back pain. Pain. 1994;57:317-26.

16. Radloff LS. The CES-D scale: A self-report depression scale for research in the general population. Appl Psych Meas. 1977;3:385-401.

17. Hautzinger M, Bailer M. ADS, Allgemeine Depressions Skala. Manual. [Center for Epidemiological Studies Depression Scale, German Version. Manual]. Weinheim: Beltz Test; 1993.

18. Bullinger M, Kirchberger I. SF-36 Fragebogen zum Gesundheitszustand Handanweisung. [SF-36 Health Survey, German Version: Handbook]. Göttingen: Hogrefe-Verlag; 1998.

19. Feise RJ. Do multiple outcome measures require p-value adjustment? BMC Med Res Methodol. 2002;2:8.

20. Cohen J. Statistical power analysis for the behavioral sciences. 2nd ed. Hillsdale, NJ: Lawrence Erlbaum; 1988.

21. McDowell I, Newell C. Measuring health. A guide to rating scales and questionnaires. 2nd ed. New York: Oxford University Press; 1996.

22. Lang E, Eisele R, Jankowsky H, et al. Ergebnisqualität in der ambulanten Versorgung von Patienten mit chronischen Rückenschmerzen. [Outcome quality of treatment for chronic low back pain under primary care conditions]. Schmerz. 2000;14(3):146-159.

23. Valat JP, Goupille P, Vedere V. Low back pain: risk factors for chronicity. Rev Rhum Engl Ed. 1997;64(3):189-194.

24. Hamre HJ, Witt CM, Glockmann A, Ziegler R, Willich SN, Kiene H. Anthroposophic therapy for chronic depression: a four-year prospective cohort study. BMC Psychiatry. 2006;6:57.

25. Weber A, Weber U, Raspe H. Medizinische Rehabilitation bei Langzeitarbeitsunfähigkeit. [Medical rehabilitation in long-term disability]. Rehabilitation (Stuttg). 1999;38(4):220-226.

26. Hansson TH, Hansson EK. The effects of common medical interventions on pain, back function, and work resumption in patients with chronic low back pain: A prospective 2-year cohort study in six countries. Spine. 2000;25(23):3055-3064.
27. Hoopmann M, Reichle C, Krauth C, Schwartz FW, Walter U. Effekte eine Rückenschulprogrammes der AOK Niedersachsen auf die Entwicklung der gesundheitsbezogenen Lebensqualität sowie der Arbeitsunfähigkeit. [Effect of a back education program by the Lower Saxony AOK in response to the development of health related quality of life and occupational disability]. Gesundheitswesen. 2001;63(3):176-182.

28. Bahrke U, Bandemer-Greulich U, Fikentscher E, Müller K, Schreiber B, Konzag TA. Chronischer Rückenschmerz mit suppressiver Schmerzverarbeitung. Zur Optimierung des Rehabilitationserfolgs einer bislang vernachlässigten Rehabilitandengruppe. Rehabilitation (Stuttg). 2006;45(6):336-344.

29. Brauns H, Steinmann H. Educational Reform in France, West-Germany and the United Kingdom: updating the CASMIN educational classification. Mannheim: Mannheimer Zentrum für Europäische Sozialforschung; 1997.

30. Bundesgesundheitssurvey 1998. Public Use File [Federal Health Survey 1998. Public Use File]. Berlin: Robert Koch Institute; 2000.

31. Federal Statistical Office. Statistical Yearbook for the Federal Republic of Germany. Stuttgart: Metzler-Poeschel Verlag; 2001.

32. Hoffmeister H, Schelp FP, Mensink GB, Dietz E, Bohning D. The relationship between alcohol consumption, health indicators and mortality in the German population. Int J Epidemiol. 1999;28(6):1066-1072.

33. Junge B, Nagel M. Das Rauchverhalten in Deutschland. [Smoking behavior in Germany]. Gesundheitswesen. 1999;61(Sonderheft 2):S121-S125.

34. Breckenkamp J, Laaser U, Danell T. Freizeitinteressen und subjektive Gesundheit. [Hobbies and Subjective Health]. Wiesbaden: Federal Institute for Population research at the Federal Statistical Office; 2001.

35. VDR Statistik Rentenbestand am 31. Dezember 2000. [VDR-Statistics of Pensioners on December 31, 2000]. Berlin: Association of German Pension Insurance Companies; 2005.

36. Bergmann E, Ellert U. Sehhilfen, Hörhilfen und Schwerbehinderung. [Seeing aids, hearing aids, and disabilities]. Bundesgesundheitsblatt. 2000;(6):432.

37. Ministry of Health and Social Welfare. Arbeitsunfähigkeits-, Krankengeldund Krankenhausfälle und-tage nach der GKV-Statistik KG2 1996 bis 2002. [Number of cases and days with sick leave and with inpatient hospitalisation, according to the statistics of the Statutory Health Insurance KG2, 1996 to 2002]. Bonn: Ministry of Health and Social Welfare; 2003.

38. Raspe HH, Kohlmann T. Die aktuelle Rückenschmerzepidemie. [The current backache epidemic]. Ther Umsch. 1994;51(6):367-374.
Journal of Pain Research

\section{Publish your work in this journal}

The Journal of Pain Research is an international, peer-reviewed, open access, online journal that welcomes laboratory and clinical findings in the fields of pain research and the prevention and management of pain. Original research, reviews, symposium reports, hypothesis formation and commentaries are all considered for publication.

\section{Dovepress}

The manuscript management system is completely online and includes a very quick and fair peer-review system, which is all easy to use. Visit http://www.dovepress.com/testimonials.php to read real quotes from published authors. 